\title{
Development and Optimization of a Glucose Biosensor Based on Tris[5-amino-1,10-Phenanthroline]Iron(II) Polymer Films
}

\author{
Kenneth L. Brown ${ }^{1}$, Kyle A. Cushman ${ }^{1}$ \\ ${ }^{1}$ Hope College, Department of Chemistry, Holland, Michigan \\ Correspondence: Kenneth L. Brown, Hope College, Holland, MI 49423, USA. E-mail: brownk@hope.edu
}

Received: January 10, 2018 Accepted: March 20, 2018 Online Published: April 11, 2018

doi:10.5539/ijc.v10n2p16

URL: https://doi.org/10.5539/ijc.v10n2p16

\begin{abstract}
A bilayered glucose biosensor consisting of tris[5-amino-1, 10-phenanthroline]iron(II) polymer film redox mediator and a glucose oxidase layer was prepared on glassy carbon surfaces. The polymer film of the iron complex was immobilized onto the electrode using cyclic voltammetry via electropolymerization reactions, while the enzyme layer was formed using a BSA and glutaraldehyde crosslinking reaction. The biosensors gave the largest response in the $\mathrm{pH}$ range of 7-8 and were evaluated with respect to storage conditions of room temperature and $4^{\circ} \mathrm{C}$. There was no significant difference between the detection of glucose using the biosensor stored at room temperature versus one stored at $4^{\circ} \mathrm{C}$ and both bilayered films remained active for 20 days. The detection limit of the biosensors was found to be $0.30 \mathrm{mM}$ which corresponds to a signal to noise ratio of $3: 1$.
\end{abstract}

Keywords: glucose biosensor, electropolymerization, polymer thin film

\section{Introduction}

Diabetes is a metabolic world-wide disease that results in high blood sugar. The Center for Disease Control (CDC) reports that the estimated economic burden linked with prediabetes, gestational diabetes, and diagnosed diabetes cost the U.S. $\$ 322$ billion in 2012. The CDC also states that cost alone in treating diabetes was $\$ 245$ billion in 2014. There are numerous complications that come with diabetes including hypertension, blindness, kidney disease, and an increase risk for a stroke or heart attack. So, the need to monitor blood glucose levels for these people is very clear and necessary. Biosensors are devices that have the ability to do this. Specifically, enzyme-based biosensors are of great importance for their ability to detect important biological molecules (Shen et al. 2017; Nakabayashi et al. 1998; Chuang et al. 1997; Chi and Dong 1993; Creager and Olsen 1995; Shigehara et al. 1981; Battaglini et al. 1999; Dong et al. 1991; Janarthanan and Mottola 1998; Ohara et al. 1994; Mafatle and Nyokong 1997). Some of these biosensors are based on using oxygen as a redox mediator and then detecting the by-product hydrogen peroxide. The drawback in this design is that oxygen levels vary, causing hydrogen peroxide levels and hence analytical signals to fluctuate. Other amperometric biosensors use redox mediators that are electrostatically linked to a polymer backbone. In these latter cases, there is the possibility that the redox mediator can leach from the polymer network attached to the electrode. The process of immobilizing a redox mediator into a hydrogel requires approximately 48 hours to complete (Battaglini et al. 1999), whereas in our electrode modification process, the time is shortened to 6-8 hours, and the electrode is ready to use in one day; electropolymerization of the redox mediator described in this paper takes several minutes to complete. Preparation of a biosensor using ferrocene and an enzyme in a hydrogel matrix is complex and requires more than eight hours to cure the film under vacuum (Chuang, et al, 1997). The goal in this research was to develop a process in designing a biosensor within several hours as opposed to several days. The entire immobilization processs takes less than 10 minutes and the electrode is ready to use the same day. In addition, we show that the electrode can be stored in room temperature or in a cold environment and the biosensor still maintains activity over a 20-day time frame; these biosensors do not need to a prepared each day, but are designed for long-term use.

The glucose biosensor developed in this research is based on a multi-layered stepwise mechanism (Emr et al, 1995). These layers consist of an enzyme layer, redox mediator, and finally the electrode surface. Immobilization of compounds onto electrode surfaces via electropolymerization is a versatile method that can produce robust polymer films consistent in thickness and electrochemical reactivity. The compound used in this research contains multiple $-\mathrm{NH}_{2}$ groups that allow extensive crosslinking possibilities. Electroplymerization of this compound produces a three-dimensional network of active sites for reactions to occur. In this paper, the construction of the redox polymer film based on tris[5-amino-1, 10-phenanthroline]iron(II), Fe(Phen- $\left.\mathrm{NH}_{2}\right)_{3}$ (Figure 1) and an enzyme layer is examined. Cyclic 
and hydrodynamic voltammetry were used to examine the response of the biosensor in the presence of glucose. The effects of biosensor storage at different temperatures and $\mathrm{pH}$ were examined on the response of the biosensor.

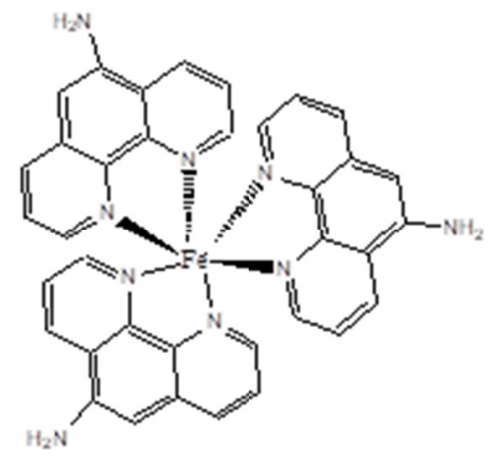

Figure 1. Tris[5-amino-1,10-phenanthroline]Iron(II)

\section{Method}

\subsection{Reagents, Solutions, and Instrumentation}

The $\mathrm{Fe}\left(\mathrm{Phen}-\mathrm{NH}_{2}\right)_{3}$ complex was synthesized according to published procedures. Glucose oxidase (GluOx, 128,200 units/g, Type X-S: Aspergillus niger), bovine serum albumin (BSA, lyophilized powder, $\geq 96 \%$ ), and glutaraldehyde (50\% in $\mathrm{H}_{2} \mathrm{O}$ ) used to construct the enzyme layer film were obtained from Sigma-Aldrich (St. Louis, MO., USA). Potassium hydrogen phosphate used to prepare the buffer solution and glucose used for detection were also purchased from Sigma-Aldrich. The tetraethylammonium perchlorate (TEAP), used as supporting electrolyte, was from GFS Chemicals (Columbus, Ohio, USA). The acetonitrile used as solvent for electropolymerization was purchased from Fisher Scientific. The water used for solution preparation was purified by reverse osmosis. All electrochemical and electropolymerizations measurements were performed with the Wavenow Potentiostat (Pine Research Instrumentation, Durham, NC). A three-electrode electrochemical cell was used consisting of a glassy carbon working electrode (diameter $=3 \mathrm{~mm}$ ), a platinum auxiliary electrode, and a $\mathrm{Ag} / \mathrm{AgCl}, 3 \mathrm{M} \mathrm{NaCl}$ reference electrode. All electrodes were obtained by Bioanalytical Systems (West Lafayette, IN). All pH measurements were made with a Jenco $\mathrm{pH}$ meter.

\subsection{Experimental}

\subsubsection{Electropolymerization of Fe Complex and Characterization of Polymer Film}

The formation of the redox polymer film of $\mathrm{Fe}\left(\mathrm{Phen}-\mathrm{NH}_{2}\right)_{3}$ was completed by electropolymerization reactions using cyclic voltammetry (CV) (Brown et al. 2002). The electropolymerization was done on glassy carbon electrodes using $\mathrm{CV}$ in a solution of $2.00 \times 10^{-3} \mathrm{M}$ of $\mathrm{Fe}\left(\mathrm{Phen}-\mathrm{NH}_{2}\right)_{3}$ in $0.10 \mathrm{M}$ tetraethylammonium perchlorate (TEAP) in acetonitrile. A potential window of 2.00 to $0.00 \mathrm{~V}$ and a scan rate of $100 \mathrm{mV} / \mathrm{sec}$ for eight cycles was used for electropolymerization. Cyclic voltammetry and hydrodynamic voltammetry were used to electrochemically characterize the polymer film in a supporting electrolyte solution of $0.10 \mathrm{M}$ TEAP in acetonitrile. Starting the potential at either $2.00 \mathrm{~V}$ or $0.00 \mathrm{~V}$ made no difference in the ability to form the polymer film or the polymer film stability in solution upon electrochemical stimulation. Characterization was performed for two cycles at a scan rate of $10 \mathrm{mV} / \mathrm{sec}$ in a potential window of $2.00 \mathrm{~V}$ to $0.00 \mathrm{~V}$.

\subsubsection{Enzyme Layer Formation}

The enzyme layer was made by drop casting three components onto the surface of the electrode: $25 \mathrm{mg} / \mathrm{mL}$ glucose oxidase (GluOx), $50 \mathrm{mg} / \mathrm{mL}$ bovine serum albumin (BSA), and glutaraldehyde (Kurita et al. 2004). The GluOx and BSA were both dissolved in a solution of $0.10 \mathrm{M}$ phosphate buffer of $\mathrm{pH} 7.4$; initially, $1 \%$ glutaraldehyde was used. Glucose oxidase and BSA both in the amount of $10 \mu \mathrm{L}$ each were placed onto the electrode. After ten minutes, $10 \mu \mathrm{L}$ of glutaraldehyde were placed on the GluOX and BSA dropwise. A film was formed but immediately degraded off into a solution containing glucose. A range of concentrations of glutaraldehyde was used to form a film. It was observed that $0.25 \%$ glutaraldehyde was the optimal concentration for successful film formation. The electrode was ready to use within eight hours.

\subsubsection{Glucose Detection}

After the enzyme layer formed, detection of glucose was achieved using cyclic voltammetry and hydrodynamic 
voltammetry. For cyclic voltammetry, glucose was detected from a solution of glucose dissolved in $0.10 \mathrm{M}$ phosphate buffer of $\mathrm{pH} 7.4$. Cyclic voltammetry was performed in a potential window of 2.00 to $0.00 \mathrm{~V}$ with a scan rate of 25 $\mathrm{mV} / \mathrm{s}$ for two cycles. An oxidation peak was observed at $1.050 \mathrm{~V}$. This potential was used in hydrodynamic voltammetry under constant stirring of the solution. After the background current stabilized, a $125 \mu \mathrm{L}$ injection of $0.050 \mathrm{M}$ glucose in the same phosphate buffer was introduced to the system.

\section{Results}

\subsection{Electropolymerization and Electrochemical Characterization}

Figure 2 illustrates the electropolymerization of the iron-phenanthroline complex. The reduction and oxidation peaks correspond to $\mathrm{Fe}^{2+} \rightleftharpoons \mathrm{Fe}^{3+}+\mathrm{e}^{-}$. The cathodic and anodic peaks appear at ca. $1.200 \mathrm{~V}$ and $1.340 \mathrm{~V}$, respectively, on the first cycle of electropolymerization. The peak separation, denoted as $\Delta \mathrm{E}_{\mathrm{p}}$, of the first and last cycles are 0.140 and 0.270 $\mathrm{V}$. Hence the electrochemistry of the iron redox processes become more quasireversible as the electropolymerization process continues. The overall change in these potentials is the result of uncompensated resistance as the film increases in thickness, and/or movement of counterions in the film during its formation. The electropolymerization of the iron complex was investigated by looking at the effect of scan rate on the peak currents. Two cycles of electropolymerization from $2.00 \mathrm{~V}$ to $0.00 \mathrm{~V}$ were completed at scan rates from 25 to $200 \mathrm{mV} / \mathrm{sec}$. Plots of the peak currents for the oxidation and reduction with respect to the square root of the scan rate in Figure 3 are linear. The linear trends of both the reduction and oxidation peak currents indicate that diffusion controlled conditions dominate the mass transfer mechanism of the redox mediator to the electrode surface during electropolymerization (Brown et al. 2002).

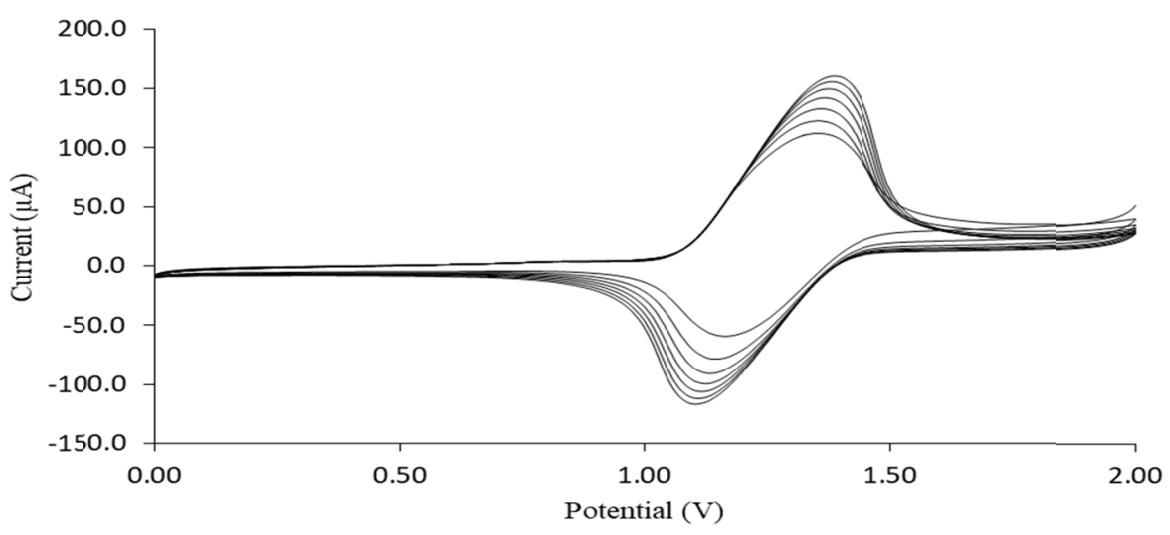

Figure 2. Cyclic voltammogram of $2.00 \times 10^{-3} \mathrm{M} \mathrm{Fe}\left(\mathrm{Phen}-\mathrm{NH}_{2}\right)_{3}$ in $01.0 \mathrm{M}$ TEAP in acetonitrile, and a scan rate of 100 $\mathrm{mV} / \mathrm{sec}$ for eight cycles in a potential window of $2.00 \mathrm{~V}$ to $0.00 \mathrm{~V}$.

\subsection{Characterization}

Figure 4 shows the characterization of the iron complex on the glassy carbon electrode. The peak separation and the formal reduction potential for the redox process $\mathrm{Fe}^{2+} \rightleftharpoons \mathrm{Fe}^{3+}+\mathrm{e}^{-}$is $0.020 \mathrm{~V}$ and $1.205 \mathrm{~V}$, respectively. The formal reduction potential was determined using $(\mathrm{Epa}+\mathrm{Epc}) / 2$. This value is in good agreement with $\mathrm{E}^{\mathrm{o}^{\prime}}$ for the same redox reaction during the electropolymerization process. No doubt that as the characterization scan rate decreases, the peak separation will also decrease as more time is allowed for the charge transfer process to occur, relative to the time scale of the cyclic voltammogram. The small peak separation indicates good charge transfer within the thin film. The electrochemical response of the film is a result of electron self-exchange reactions or "electron hopping" between the redox centers. Also, the anodic and cathodic peaks are symmetrical, but the peak width at half-height is greater than the theoretical value of $90.4 \mathrm{mV}$. 


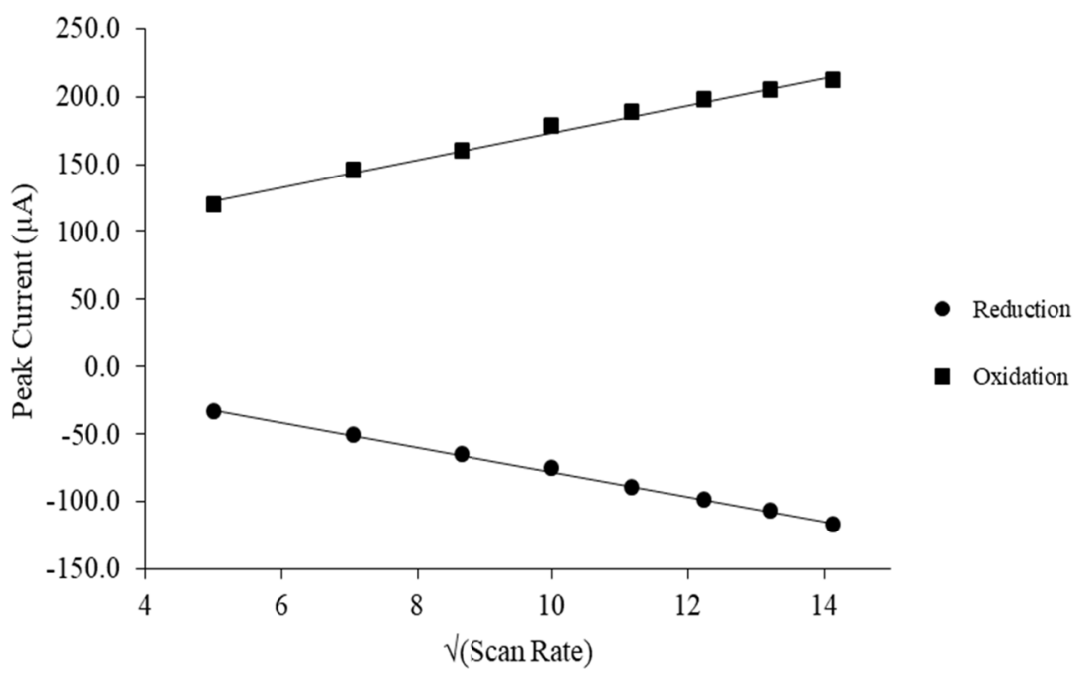

Figure 3. Effect of scan rate on peak current. A solution of $2.00 \times 10^{-3} \mathrm{M} \mathrm{Fe}\left(\mathrm{Phen}-\mathrm{NH}_{2}\right)_{3}$ in $0.10 \mathrm{M}$ TEAP in acetonitrile was used. Scan rates: $25 \mathrm{mV} / \mathrm{sec}-200 \mathrm{mV} / \mathrm{sec}$. Potential window of $2.00 \mathrm{~V}$ to $0.00 \mathrm{~V}$ was used.

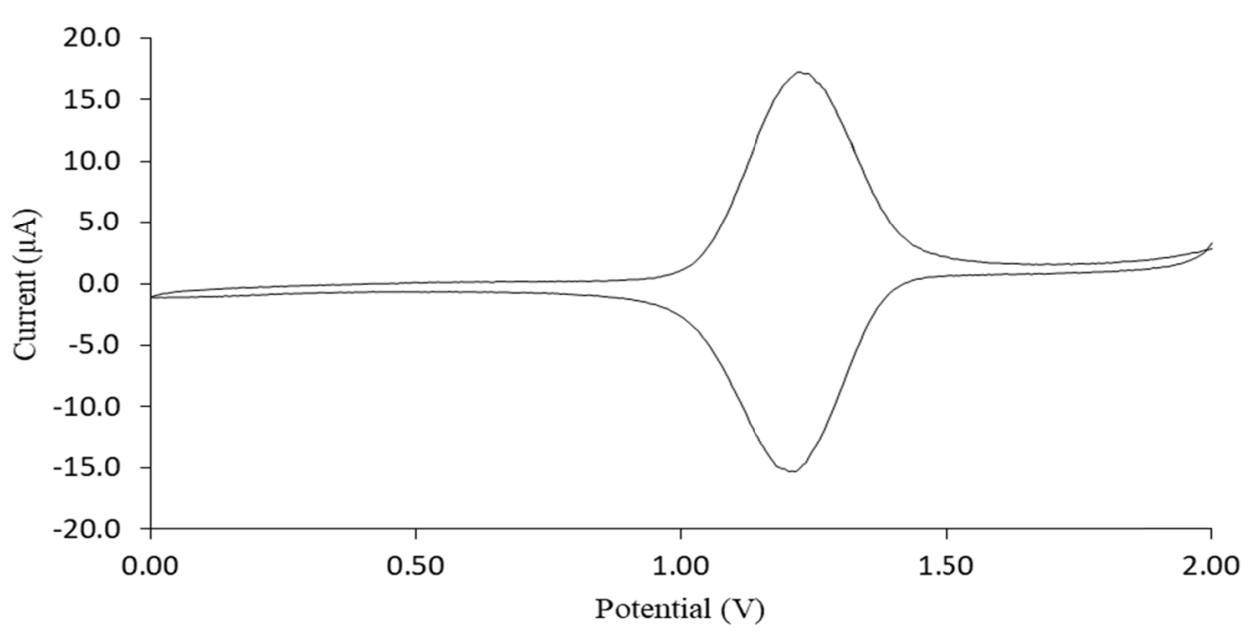

Figure 4. Cyclic voltammogram of GCE containing the polymer film of $\mathrm{Fe}\left(\mathrm{Phen}-\mathrm{NH}_{2}\right)_{3}$ in $0.10 \mathrm{M}$ TEAP in acetonitrile and a scan rate of $10 \mathrm{mV} / \mathrm{sec}$ with a potential window of $2.00 \mathrm{~V}$ to $0.00 \mathrm{~V}$.

This has been attributed to non-equivalent redox centers or the presence of attractive or repulsive forces with the films (Anson et al, 1981). Previous results indicate the films do not grow in regular layers and hence it is unlikely that there is an even distribution of redox centers across the film, both laterally and longitudinally. One characterization CV was completed from $2.00 \mathrm{~V}$ to $0.00 \mathrm{~V}$ at a range of scan rates. The scan rates used ranged from $10 \mathrm{mV} / \mathrm{sec}$ to $100 \mathrm{mV} / \mathrm{sec}$ at $20 \mathrm{mV} / \mathrm{sec}$ intervals. The linear trends of both the reduction and oxidation peak currents with respect to the scan rate confirm good charge transfer as shown in Figure 5.

\subsection{Glucose Detection}

Cyclic voltammetry was used as the initial method to characterize the bilayered electrode in buffered solutions of glucose. Figure 6 shows an overlay of three characterization cyclic voltammograms in 1.00, 2.00, and $3.00 \mathrm{mM}$ glucose solutions. 


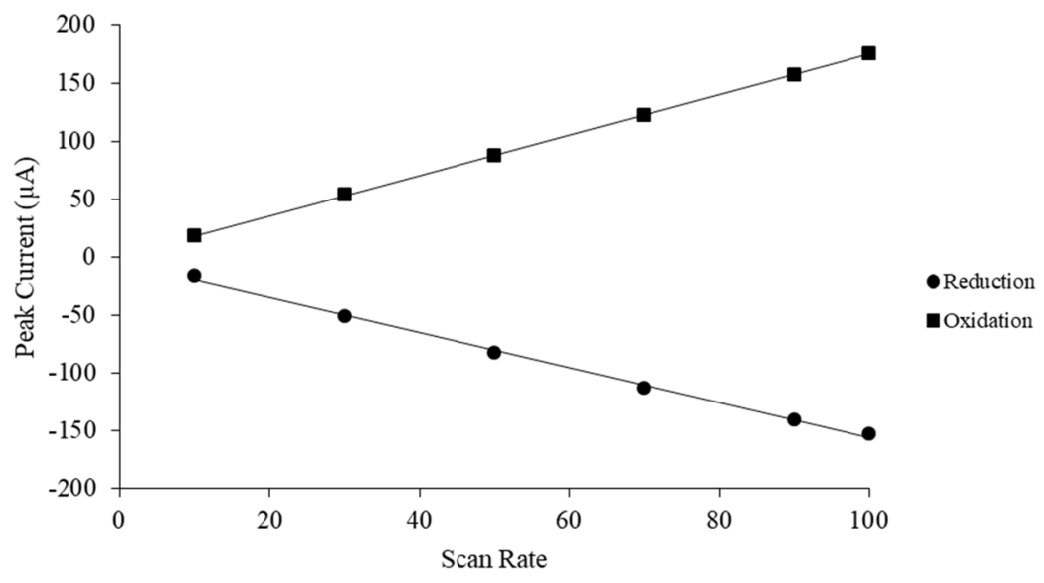

Figure 5. Effect of scan rate on peak current of the iron redox polymer film on a glassy carbon electrode. A supporting electrolyte solution of $0.10 \mathrm{M}$ TEAP in acetonitrile was used. Scan rates: $10 \mathrm{mV} / \mathrm{sec}-100 \mathrm{mV} / \mathrm{sec}$ at $20.0 \mathrm{mV} / \mathrm{sec}$ intervals.

Two cycles of characterization in the presence of glucose were completed at $25 \mathrm{mV} / \mathrm{sec}$. As the concentration of glucose increased, the peak at ca. $1.050 \mathrm{~V}$ increased. This characterization peak is near the same potential for the oxidation and reduction of the iron redox center in Figures 2 and 4. This indicates that the $\mathrm{Fe}^{2+/ 3+}$ redox couple is involved in the reactions for detecting glucose.

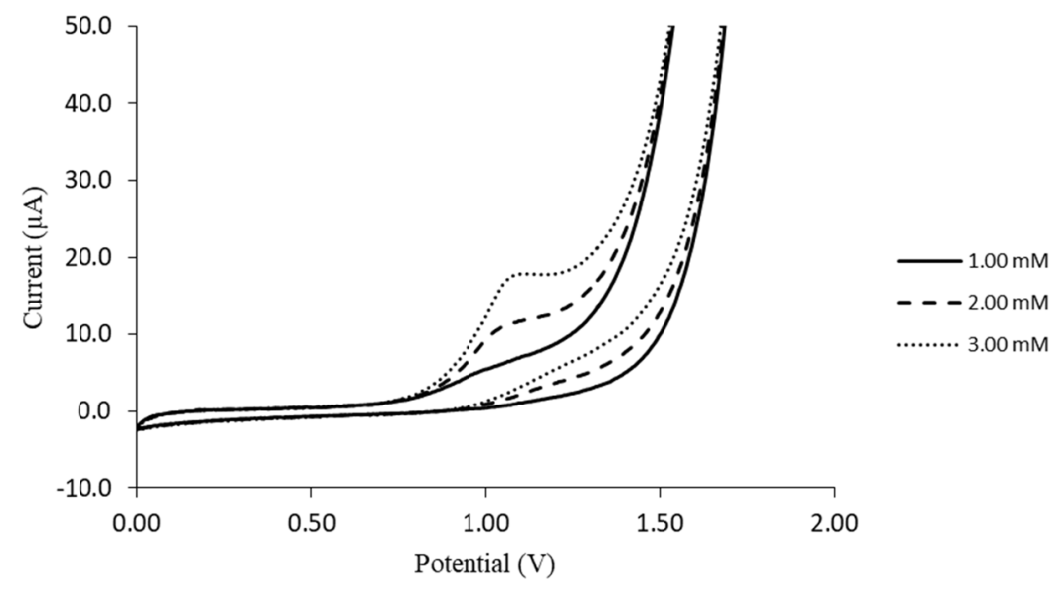

Figure 6. Overlay of cyclic voltammograms of 1.00-3.00 mM glucose detection. Two characterization cycles of glucose were completed from 2.00 to $0.00 \mathrm{~V}$ at $25 \mathrm{mV} / \mathrm{sec}$.

Typical blood glucose levels are 4.4-6.6 mM (Wang 2008). The peak currents from voltammograms were recorded and plotted with respect to the glucose concentration (Figure 7). The calibration curve equation is: $\mathrm{y}=3.51 \mu \mathrm{A} \cdot \mathrm{mM}^{-1} \mathrm{x}+$ $2.21 \mu \mathrm{A}$, with $\mathrm{R}^{2}=0.9940$. The range of standards for the calibration curve is very suitable for montinoring typical glucose levels. The potential of $1.050 \mathrm{~V}$ was used as the test potential for the hydrodynamic voltammetry studies. A current response was observed after an injection of glucose to the system. Each step-wise change in current is the result of glucose being introduced to the system (Figure 8). The response of the biosensor towards glucose was less than 1 second. However, it required approximately 5 seconds for the response current to reach a steady-state value. This response time and time reach steady state is better than others (e.g, 10 seconds or longer). The detection limit of 0.30 $\mathrm{mM}$ was determined as the concentration of glucose that provided a signal to noise ratio of 3 . 


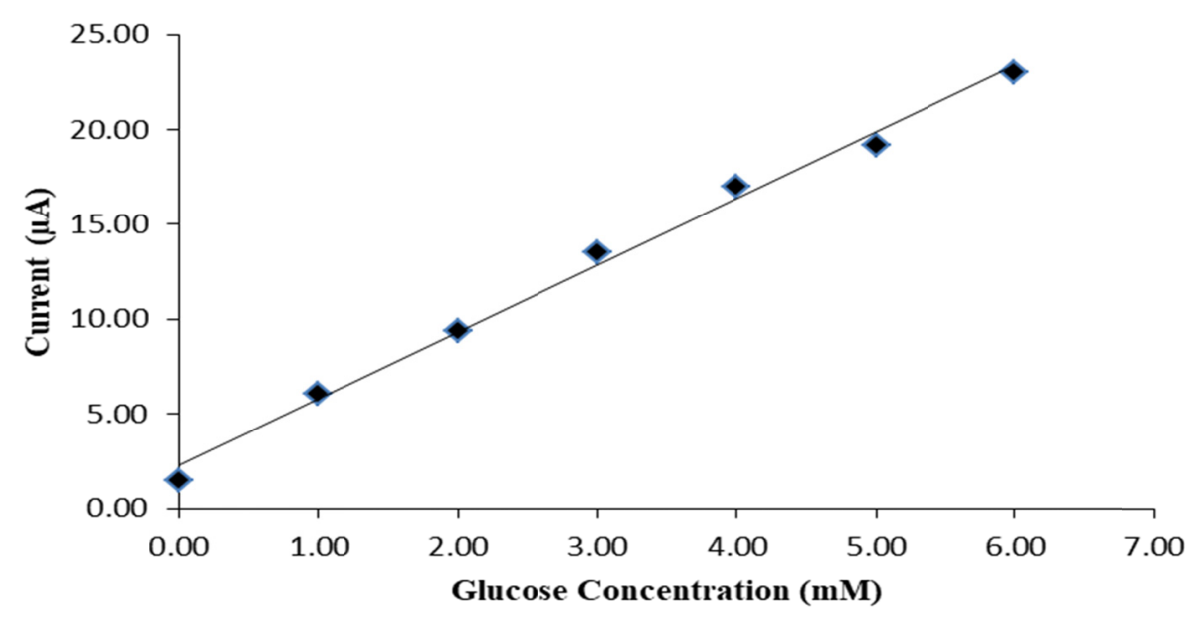

Figure 7. Linear current response with respect to concentration of glucose. The range of concentration of glucose measured was $0.00-6.00 \mathrm{mM}$ at $1.050 \mathrm{~V}$. The calibration curve equation: $\mathrm{y}=3.51 \mu \mathrm{A} . \mathrm{mM}^{-1} \mathrm{x}+2.21 \mu \mathrm{A}$, with

$$
\mathrm{R}^{2}=0.9940
$$

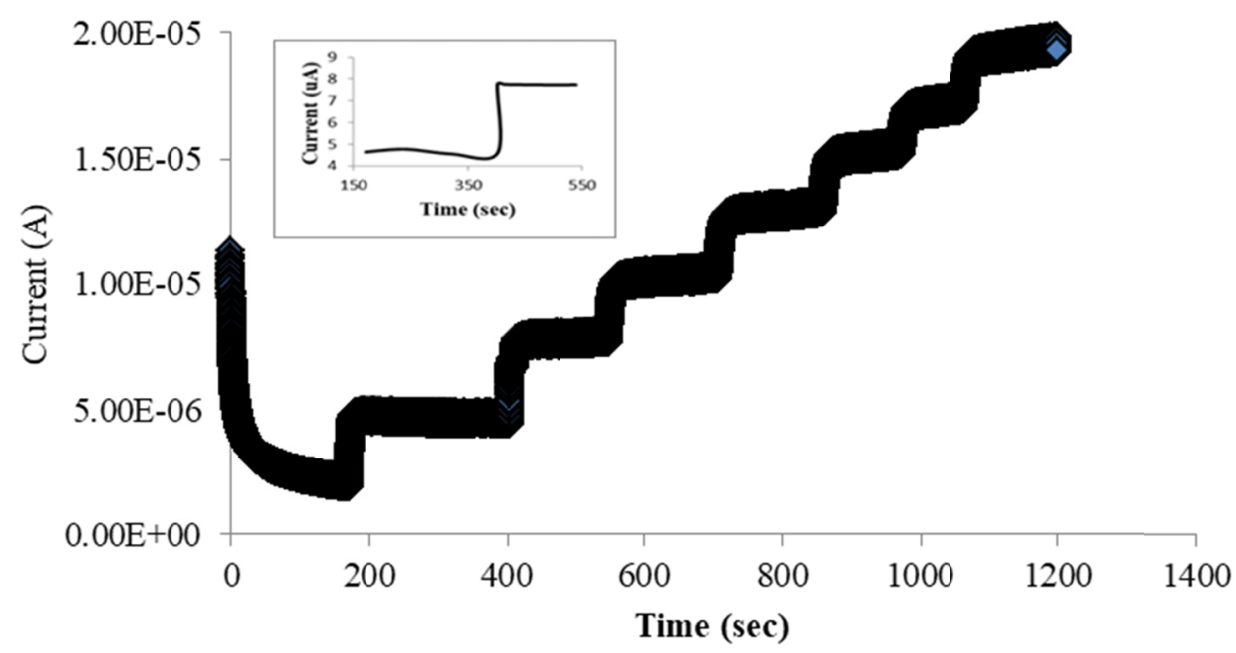

Figure 8. Hydrodynamic voltammogram at an applied potential of $1.050 \mathrm{~V}$ (vs $\mathrm{Ag} / \mathrm{AgCl}$ ). Seven, $125 \mu \mathrm{L}$ injections of $0.050 \mathrm{M}$ glucose were introduced to the system

The reactions related to the detection of glucose using this system are described by equations (1)-(3):

$$
\begin{gathered}
\mathrm{GOx}(\mathrm{FAD})+\text { Glucose } \rightarrow \mathrm{GOx}\left(\mathrm{FADH}_{2}\right)+\text { gluconolactone } \\
\mathrm{GOx}\left(\mathrm{FADH}_{2}\right)+2 \mathrm{Fe}^{3+} \rightarrow \mathrm{GOx}(\mathrm{FAD})+2 \mathrm{Fe}^{2+}+2 \mathrm{H}^{+} \\
2 \mathrm{Fe}^{2+} \rightarrow 2 \mathrm{Fe}^{3+}+2 \mathrm{e}-
\end{gathered}
$$

In equations (2)-(3), the focus is placed on the redox transformation of iron $\left(\mathrm{Fe}^{3+/ 2+}\right)$ in the $\mathrm{Fe}\left(\mathrm{Phen}-\mathrm{NH}_{2}\right)_{3}$ complex because the Phen- $\mathrm{NH}_{2}$ ligand system does not undergo a reduction or oxidation within the potential window used. In equation 1, the glucose undergoes an oxidation via the enzyme, and then the reduced form of the enzyme $\operatorname{GOx}\left(\mathrm{FADH}_{2}\right)$ becomes oxidized by the film as shown in equation 2. The response of the film in equation 3 gives rise to the analytical signal observed. The inset hydrodynamic diagram shows that the biosensor reaches a steady-state current within 9 seconds. During this time frame, the current varies between 7.74-7.78 $\mu \mathrm{A}$ and thereafter, until the next injection of glucose. In approximately 5 seconds the current has reached a value of $7.74 \mu \mathrm{A}$ and only changes to $7.78 \mu \mathrm{A}$ within 9 seconds. This is slightly better than those reported using other methods of redox mediator immobilization strategies.

\section{$3.4 \mathrm{pH}$ Study}

The effect of $\mathrm{pH}$ on detection of glucose was studied as enzymatic activity can be affected by $\mathrm{pH}$ and at certain $\mathrm{pH}$ 
levels, the enzyme can begin to denature. This study helped gain an understanding how the enzyme layer of

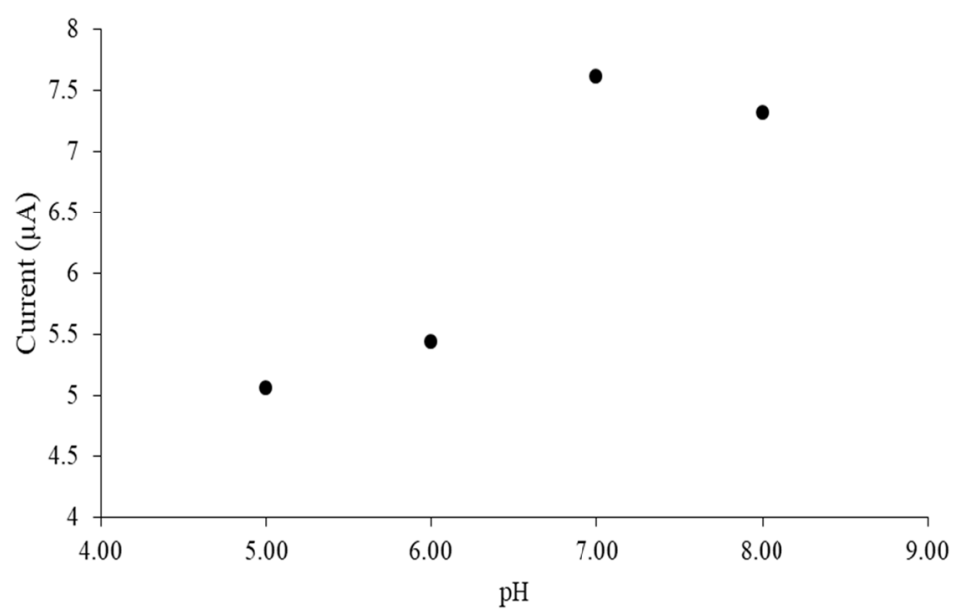

Figure 9. Plot of current change with respect to $\mathrm{pH}$. The $\mathrm{pH}$ measured ranged from 5.00-8.00. The highest current response was at $\mathrm{pH} 7.00$.

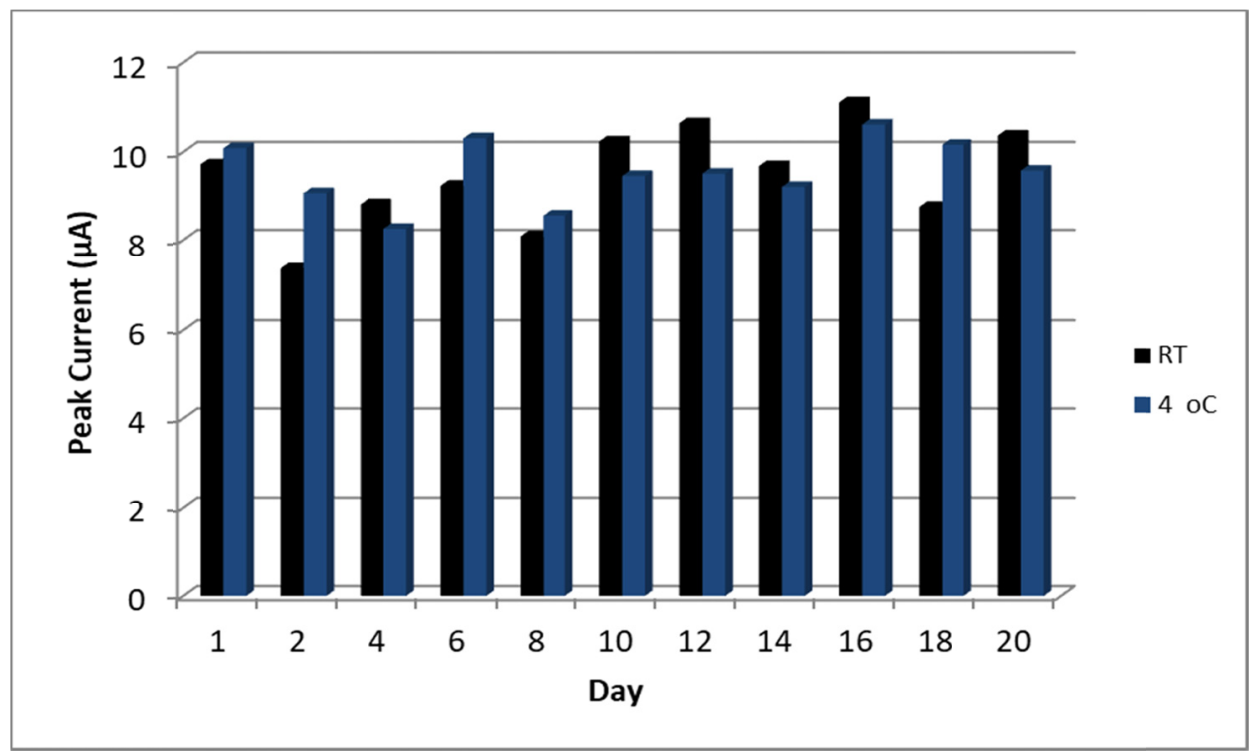

Figure 10. Graph showing the variation of the glucose response for two modified electrodes with glucose oxidase and $\mathrm{Fe}\left(\mathrm{Phen}-\mathrm{NH}_{2}\right)_{3}$ at room temperature and $4^{\circ} \mathrm{C}$.

The biosensor behaved in varying $\mathrm{pH}$ levels. Four different solutions of $6 \mathrm{mM}$ glucose were made in $0.10 \mathrm{M}$ phosphate buffer at $\mathrm{pH} 5.00,6.00,7.00$, and 8.00. Detection of glucose was performed using CV. Two cycles were completed from 2.00 to $0.00 \mathrm{~V}$ at $25 \mathrm{mV} / \mathrm{sec}$. As seen in Figure 9, the highest current response occurs at a $\mathrm{pH}$ of 7 . It is predicted that this relationship has a bell-shaped curve, peaking between $\mathrm{pH} 7$ and 8 . The $\mathrm{pH}$ of blood spans from 7.35-7.45 which is in this range (Effros et al. 2010).

\subsection{Temperature Storage Study}

Two biosensors were constructed to study how long the devices could detect glucose and the effect of storing the devices at different temperatures. One was stored at room temperature (RT) and the other at $4^{\circ} \mathrm{C}$ as shown in Figure 10 . For twenty days, each biosensor was used to detect $3 \mathrm{mM}$ glucose by $\mathrm{CV}$. After their usage, they were both safely stored 
at their respective temperatures. A paired $t$-test was used to test the difference between the current response of each electrode every day they were used. Based on the paired $t$-test that at a $95 \%$ confidence level $(n=11)$, there was no significant difference between the responses of the two biosensors stored at room temperature (black graph) versus $4^{\circ} \mathrm{C}$ (blue graph).

\section{Conclusion}

In this paper, the electrochemical behavior of a $\mathrm{Fe}\left(\mathrm{Phen} \mathrm{NH}_{2}\right)_{3}$ redox polymer film in a glucose biosensor has been investigated by cyclic and hydrodynamic voltammetric techniques. Two biosensors were stored at different temperatures, one at room temperature and the other at $4^{\circ} \mathrm{C}$. Throughout 20 days of storage, both biosensors consistently detected glucose. It was observed that the biosensor performs best in the $\mathrm{pH}$ range of 7-8 which encompasses the standard blood $\mathrm{pH}$ range of 7.35-7.45. The detection limit of the biosensors is $0.30 \mathrm{mM}$. Based on the studies performed, a durable and sensitive bliayered glucose biosensor can be constructed $\mathrm{Fe}\left(\mathrm{Phen} \mathrm{NH}_{2}\right)_{3}$ as a redox mediator.

\section{References}

Battaglini, F., Calvo, E. J., Danilowicz, C., \& Wolosiuk, A. (1999). Effect of ionic strength on the behavior of amperometric enzyme electrodes mediated by redox hydrogels. Anal. Chem., 71, 1062-1067. https://doi.org/10.1021/ac971253m

Brown, K., Shaw, J., Ambrose, M., \& Mottola, H.A. (2002). Voltammetric, chronocoulometric and spectroelectrochemical studies of electropolymerized films based on $\mathrm{Co}(\mathrm{III} / \mathrm{II})$ - and $\mathrm{Zn}$ (II) 4,9,16,23-tetraaminophthalocyanine: effect of high pH. Microchem. J. 72, 285-298. https://doi.org/10.1016/S0026-265X(02)00042-5

Centers for Disease Control and Prevention. (2014). National Diabetes Statistics Report: Estimates of Diabetes and Its Burden in the United States, Atlanta, GA: U.S. Department of Health and Human Services.

Chi, Q., \& Dong, S. (1993). Flow-injection analysis of glucose at an amperometric glucose biosensor based on electrochemical codeposition of Palladium and Glucose oxidase on a glassy carbon electrode. Anal. Chim. Acta, 278, 17-23. https://doi.org/10.1016/0003-2670(93)80080-5

Chuang, C. L., Wang, Y. J., \& Lan, H. L. (1997) Amperometric glucose sensors based on ferrocene-containing B-polyethylenimine and immobilized glucose oxidase. Anal. Chim. Acta, 353, 37-44. https://doi.org/10.1016/S0003-2670(97)00372-3

Cohen, R., \& Woods, H. (1976). Clinical and Biochemical Aspects of Lactic Acidosis. London, United Kingdom: Blackwell Scientific Publications.

Creager, S. E., \& Olsen, K. G. (1995). Self-assembled monolayers and enzyme electrodes: progress, problems, and prospects. Anal. Chim. Acta, 307, 277-289. https://doi.org/10.1016/0003-2670(94)00506-H

Dong, S., Wang, B., \& Liu, B. (1991). Amperometric glucose sensor with ferrocene as an electron transfer mediator. Biosen. Bioelectron., 7, 215-222. https://doi.org/10.1016/0956-5663(92)87018-K

Effros, R., \& Swenson, E. (2010). Acid-base balance. In: Mason RJ, Broaddus CV, Martin TR, et al. Murray \& Nadel's Textbook of Respiratory Medicine. 5th ed. Philadelphia, PA: Saunders Elsevier.

https://doi.org/10.1016/B978-1-4160-4710-0.00007-9

Emr, S., \& Yacynch, A. (1995). Use of Polymer Films in Amperometric Biosensors, Electroanalysis, 7, 913-923. https://doi.org/10.1002/elan.1140071002

Janarthanan, C., \& Mottola, H. A. (1998). Enzymatic determinations with rotating bioreactors: determination of glutamate in food products. Anal. Chim. Acta., 369, 147-155. https://doi.org/10.1016/S0003-2670(98)00202-5

Kurita, R., Tabei, H., Iwasaki, Y., Hayashi, K., Sunagawa, K., \& Niwa, O. (2004). Biocompatible glucose sensor prepared by modifying protein and vinylferrocene monomer composite membrane. Biosens Bioelectron, 20, 518-523. https://doi.org/10.1016/j.bios.2004.02.018

Mafatle, T., \& Nyokong, T. (1997). Amperometric glucose sensors fabricated by electrochemical polymerization of phenols on carbon paste electrodes containing ferrocene as an electron transfer mediator. Anal. Chim. Acta, 41, 301-314.

Nakabayashi, Y., Wakuda, M., \& Imai, H. (1998). "Wired" enzyme electrodes for amperometric determination of glucose for lactate in the presence of interfering substances. Anal. Sci., 14, 1069-1076. https://doi.org/10.2116/analsci.14.1069

Ohara, T. J., Rajagopalan, R., \& Heller, A. (1994). Spectrophotometric cell compromising parallel rotating and 
stationary bioreactors: application to the determination of glucose in serum samples. Anal. Chem., 66, 2451-2457. https://doi.org/10.1021/ac00087a008

Shigehara, K., Oyama, N., \& Anson, F. C. (1981). Electrochemical responses of electrodes coated with redox polymers. Evidence for control of charge-transfer rates across polymeric layers by electron exchange between incoroporated redox sites. J. Am. Chem. Soc., 103, 2552-2558. https://doi.org/10.1021/ja00400a011

Wang, J. (2008). Electrochemical Glucose Biosensors. Chem. Rev. 108, 814-25. https://doi.org/10.1021/cr068123a

\section{Copyrights}

Copyright for this article is retained by the author(s), with first publication rights granted to the journal.

This is an open-access article distributed under the terms and conditions of the Creative Commons Attribution license (http://creativecommons.org/licenses/by/4.0/). 